\title{
Evaluation of dump slope stability of a coal mine using artificial neural network
}

\author{
Rahul • Manoj Khandelwal $(\mathbb{D} \cdot$ \\ Rajesh Rai • B. K. Shrivastva
}

Received: 6 May 2015/ Accepted: 10 August 2015/Published online: 20 August 2015

(C) Springer International Publishing Switzerland 2015

\begin{abstract}
Dump slope stability is critical in the design and operation of any open pit mines having significant impacts on safety and on the economics of an open pit project. The issues related to the stability of dumps is catching attention worldwide from quite some time, which is quite important for the safe working in and around monstrous structures as well as restricted availability of land. In the present paper, artificial neural network (ANN) has been used to calculate the factor of safety of dump slope of a coal mine. A three-layer, feed-forward back-propagation neural network having optimum hidden neurons is used to model. The input parameters are dump slope geometry, geotechnical properties and hydrological conditions have been used to evaluate the stability of dump slope. Six input parameters and one output parameters have been trained using various algorithms. New dump slope data sets have been used for the validation and comparison of the factor of safety of dump slope. Factor of safety has also been determined using numerical modeling technique. Results were compared between factor of safety, calculated from the numerical modeling tool and predicted value of
\end{abstract}

Rahul · R. Rai · B. K. Shrivastva

Department of Mining Engineering, Indian Institute of

Technology (BHU), Varanasi 221005, India

M. Khandelwal $(\bowtie)$

Faculty of Science and Technology, Federation University Australia, PO Box 663, Ballarat, VIC 3353, Australia

e-mail: m.khandelwal@federation.edu.au factor of safety by ANN. It was found a very closer agreement between the predicted and calculated values of factor of safety for the dump slope with ANN over numerical modelling.

Keywords Dump slope · Coal mine, artificial neural network $\cdot$ Back propagation $\cdot$ Finite element method

\section{Introduction}

Since 1970s, the Indian mining industry has witnessed a sea change, particularly in Coal mining. The production of coal increase from a level of 70 MTs in early 1970 has reached to over 565 MTs in 2013-2014. The increase in production is mainly contributed by the surface coal mine and at present, more than $88 \%$ of coal production is coming from surface mines. Due to enhancement in coal production, handling volume of overburden and inter-burden material also significantly increased. This is the main reason of formation of large size spoil dumps inside and outside the mines. These large sizes of dump have become more important in view of restricted availability of land. Dumping of waste without any prior analysis has caused the waste dump failures (Koner and Chakravarty 2010). Failure of dumps is a complex problem and it directly affects the resource recovery, mine safety and mining cost. It may also cause constant danger to the men and machinery deployed in the mine with a potential to cause catastrophic loss of 
life and property. An analysis of accidents in opencast mines revealed that slope and dump failures have started assuming an upward trend in the recent times (DGMS 2010). So, detailed analysis of dump stability is now getting prime importance throughout the world.

Stability of dump slopes is dependent on many parameters, like geometry of dump slope, which includes overall dump height, overall slope angle, bench angle and number of benches; geology of dumping site; hydrological conditions of the area; geotechnical properties of dump, like cohesion, density and angle of internal friction of dumping material; method for construction of dump; nature of foundation of dump; seismic activities and vegetation (Singhal and Vladut 1987; Shakesby and Whitlow 1991; Singh and Khandelwal 2007; Ulusay et al. 2014). These are governing parameters for the stability of any dumps. Stuckert et al. (1989) studied the dynamic stability of mine waste dumps. Vrkljan et al. (1992) studied various geotechnical problems associated with the design of waste dump on soft soils.

The majority of slope stability analyses are performed by using traditional limit equilibrium (LE) approaches involving methods of slices that have remained essentially unchanged for decades. Recently, the numerical modeling technique has been developed to model strong discontinuity using standard constitutive equations and is being applied for analyzing slope stability in solid mechanics (Ugai et al. 1987; Riley 1995). It allows to model strong discontinuities which is imbedded into the element displacement field. However, it needs good knowledge of finite element or finite difference, computer programs and to have enough time to prepare input data and running computer programs (Cała and Flisiak 2003; Pourkhosravani and Kalantari 2011).

So, there is a need of the hour for a suitable and substitute method instead of LE or numerical methods with quick and accurate results. At present, Artificial Neuarl Network (ANN) technique is considered to be one of the most intelligent tools for simulating complex problems. This technique has the ability of generalizing a solution from the pattern presented to it during training. Once the network is trained with a sufficient number of sample datasets, for a new input of relatively similar pattern, predictions can be done on the basis of previous learning. Due to its multidisciplinary nature, ANN is becoming popular among the researchers, planners, designers, etc., as an effective tool for the accomplishment of their work.

Khandelwal and Singh (2002) predicted the factor of safety of dump slope using ANN and found very good correlation. Mayoraz and Vulliet (2002) used ANN to predict the slope movement and found very results. Fernando and Nag (2003) studied the internal overburden dump design and stability analysis for Hazelwood power mine, Latrobe valley, Australia. Khandelwal et al. (2008) analyzed the stability of coal mine waste dump using limit equilibrium method. Rai et al. (2012) used geo-grids to enhance the stability of waste dump and analyzed the results with numerical modeling. They found that stability of waste dump can be enhanced considerably using geo-grids at certain intervals.

ANN is having high flexibility in learning such type of complex problems. ANN has the advantage of LE and numerical methods together and also improves the defect and short coming of LE and numerical methods (Pourkhosravani and Kalantari 2011).

So, in the present paper, a three layer feed forward back propagation ANN has been used to analyze and evaluate the stability of dump slopes using slope profile, geotechnical and hydrological parameters. ANN results were also compared with numerical modelling output to get higher confidence.

\section{Artificial neural network (ANN)}

Artificial neural network is a branch of the 'artificial intelligence', which also includes case-based reasoning, expert systems, and genetic algorithms. The classical statistics, fuzzy logic and chaos theory are also considered to be related fields. ANN is an information processing system simulating the structure and functions of the human brain. It is a highly interconnected structure that consists of many simple processing elements (called neurons) capable of performing massively parallel computation for data processing and knowledge representation. The ANN is first trained by processing a large number of input patterns and the corresponding output. The ANN is able to recognize similarities when presented with a new input pattern after proper training and predicting the output pattern. 


\section{Network training}

A network first needs to be trained before interpreting new information. A number of algorithms are available for training of ANN but the back-propagation algorithm is the most versatile and robust technique. It provides the most efficient learning procedure for multilayer ANN. The feed forward back-propagation neural network (BPNN) always consists of at least three layers: input layer, hidden layer and output layer. Each layer consists of a number of elementary processing units, called neurons, and each neuron is connected to the next layer through weights, i.e. neurons in the input layer will send their output as input to neurons in the hidden layer and similar is the connection between hidden and output layer. Number of hidden layers and neurons in the hidden layer is changed according to the problem to be solved. The number of input and output neuron is the same as the number of input and output variables.

During training of the network, data is processed through the input layer to hidden layer, until it reaches the output layer (forward pass). In this layer, the output is compared to the measured values (the "true" output). The difference or error between both is propagated back through the network (backward pass) updating the individual weights of the connections and the biases of the individual neurons. The input and output data are mostly represented as vectors called training pairs. The process as mentioned above is repeated for all the training pairs in the data set, until the network error converges to a threshold defined by a corresponding function; usually the root mean squared error (RMS) or summed squared error (SSE) (Fig. 1).

In the training process, the interconnections between the neurons are initially assigned specific weights. The network would be able to perform a particular function by adjusting the initial weights (Demuth et al. 2002). A single neuron containing multiple inputs $\left(\mathrm{x}_{1}, \ldots, \mathrm{x}_{\mathrm{n}}\right)$ and a single output $(\mathrm{y})$ is shown in Fig. 2. The ANN network can be defined by three fundamental components: transfer function, network architecture, and learning law. There are different types of transfer function functions (nonlinear and/or linear) are purelin, logsig, and hardlim. There are many types of network used in simulation of various problems by ANN, feedforward neural network, redial basis function network, and recurrent network are generally used so formulate the problems by ANN. Basically the ANN architecture include number of hidden layer, number of hidden nodes, number of output nodes and activation function. The learning law can be categorized in three distinct sorts supervised learning or associative learning, unsupervised learning or self-organization and reinforcement Learning. However selection of the function is performed according to the problem to be solved. Each input is weighted with an appropriate w. The sum of the weighted inputs and the bias forms the input to the transfer function $\mathrm{f}$.

$a=\sum_{i=1}^{n} x_{i} w_{i}+b$

A large number of hidden layer nodes have large number of associated undetermined parameters, and if the number of training pairs is small, the network will then tend to memorize rather than generalize. Seibi and Al-Alawi (1997) pointed out that an overdetermined network should be used in order to have a good approximation over the region of interest. ANN may be used as a direct substitute for auto correlation, multi variable regression, linear regression, and other statistical analysis and techniques. ANN, with the unremarkable ability to derive a general solution from complicated or imprecise data, and detect trends that are too.

\section{Numerical modeling of dump slope}

A number of different numerical methods exists-e.g., Boundary Element Methods (BEM), Finite Element methods (FEM) and Finite Difference Methods (FDM) (Jing and Hudson 2002). In boundary element methods, only the boundaries of a problem need to be discretized into elements. For finite element and finite difference methods, the entire problem domain must be discretized into elements. Another class of methods is the Discrete Element Method (DEM). While BEM, FEM and FDM all are continuum methods, DEM is a discontinuum method in which discontinuities present in the rock mass are modeled explicitly. In continuum models, the displacement field will always be continuous. No actual failure surface discontinuity is formed, but the location of the failure surface can be judged by the concentration of shear strain in the model (Cundall 1976; Itasca Consulting Group 1995). 
Fig. 1 A view of ANN model

$$
\text { Input Layer Hidden Layer I Hidden Layer II Output Layer }
$$

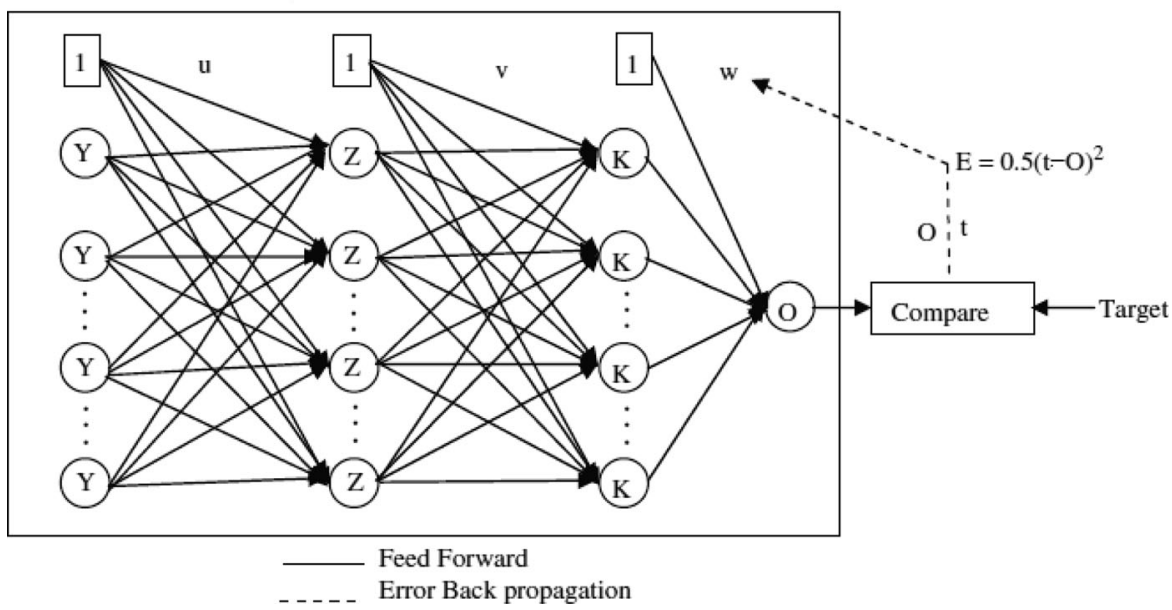

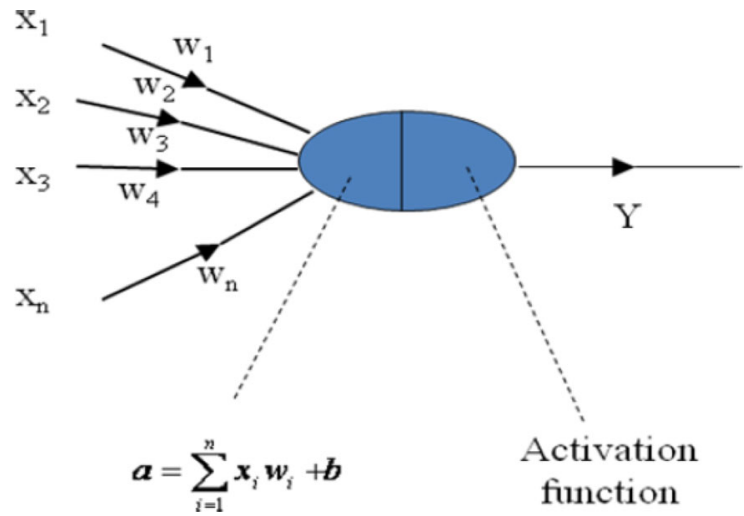

Fig. 2 Graphical representation of a single neuron

There is no need of assumption about the shape or location of the failure surface is required in advance, the probable failure circle occur naturally in numerical modeling (Finite element analysis). The progressive failure can be monitored during the simulation of numerical coal modeling. Shear Strength reduction (SSR) technique has been used in numerical modeling to calculate the factor of safety. The factor of safety of a slope is the ratio of actual soil shear strength to the minimum shear strength required to prevent failure or the factor by which soil shear strength must be reduced to bring a slope to the verge of failure (Duncan 1996). To perform slope stability analysis with the shear strength reduction technique, simulations are run for a series of increasing trial factors of safety, $\mathrm{F}^{\text {trial }}$. The actual shear strength properties cohesion (c) and internal friction angle $(\Phi)$ are reduced for each trial according to the equations given below. If the multiple materials are present, the reduction is made simultaneously for all materials. The trial factor of safety is gradually increased until the slope fails. At failure, the safety factor equals the trial safety factor. The factor of safety is defined according to the equation.

$C^{\text {trial }}=\frac{1}{F^{\text {trial }}} C$

$\phi^{\text {trial }}=\operatorname{acrtan}\left(\frac{1}{F^{\text {trial }}} \tan \phi\right)$

The Phase 2 v7.0 software based on the finite element method is used in modeling and simulation of the dump slope. The failure of the overall dump is either a failure of the dump material itself or the failure of the coal rib. Gravity loading has been applied. Nonassociated flow rule with zero volume change during yield has been used to calculate the factors of safety. The Mohr-coulomb elastic-perfectly plastic model has been considered. It based on the assumption that the principal directions of accumulated stress and incremental plastic strain coincide. It is expressed as:

$\sigma_{1}=2 \mathrm{c} \frac{\cos \phi}{1-\sin \phi}+\sigma_{3} \frac{1+\sin \phi}{1-\sin \phi}$

where, $\mathrm{c}$ and $\phi$ are cohesion and internal frictional angle $\sigma_{1}$ and $\sigma_{3}$ are principal stresses. 


\section{Input and output parameters}

Table 1 show the input and output parameters with their range for the present study. By considering all these parameters and their variations, as much as possible numbers of cases are formed and simulate all these cases by numerical modeling tool.

Initial various numbers of numerical models have been prepared and solved. The factor of safety is calculated by Strength Reduction Technique (SRT). Then the selected parameters have been used as input to developed ANN models.

In this study, ANN is used to find out the factor of safety of coal mine dump slope. Here, 520 dump slope models are used to develop ANN. The range of overall dump height, overall slope angle, number of benches, hydrological condition, cohesion of dump material, and internal angle of friction of dump material are taken as input parameters and factor of safety is considered as an output parameter for the development of ANN model.

\section{Network architecture}

Feed forward back-propagation neural network architecture is adopted here due to its appropriateness for this type of problem. The objective of the present investigation is to predict factor of safety of coal mine dump slope from relevant parameters. It is difficult to determine all the relevant parameters, which have direct influence on the factor of safety of dump slope.

Table 1 Input and output parameters with their range

\begin{tabular}{ll}
\hline Name of parameter & Range \\
\hline $\begin{array}{ll}\text { Input parameters } \\
1 \quad \text { Overall height (In meter) }\end{array}$ & $40-200$ \\
$2 \quad$ Overall slope angle & $17^{\circ}-39^{\circ}$ \\
$3 \quad$ Number of benches & $2-7$ \\
$4 \quad$ Groundwater condition & $0-50 \%$ of overall dump height \\
$\begin{array}{l}\text { Dump material quality } \\
5 \quad \text { Cohesion }\end{array}$ & $10-70 \mathrm{Kpa}$ \\
$6 \quad$ Internal angle of friction & $10^{\circ}-45^{\circ}$ \\
$\begin{array}{l}\text { Output parameter } \\
7 \quad \text { Factor of safety }\end{array}$ & $0.5-2.8$ \\
\hline
\end{tabular}

However, the influencing parameters are not independent and some of them are strongly correlated. Hence, it was not possible to use all the variables as input parameters.

A three-layer feed-forward back-propagation neural network was developed to predict the factor of safety. The input layer has 6 input neurons and the output layer has one neuron, whereas the hidden layer has 7 hidden neurons as shown in Fig. 3. Training of the network is carried out using $80 \%$ cases and testing and evaluation of the network is performed using $20 \%$ different cases. All data type which is used here to build ANN network are numeric. Tangential and exponential functions are used as transfer function.

\section{Results and discussion}

Figure 4 shows the discretized model of dump slope by finite element method. Model is descritised into uniform six nodded triangular shape elements Plane strain condition has been taken and maximum number of iteration is 500 with tolerance is 0.001 has been taken for the calculation of factor of safety. Side boundaries are restrained in $\mathrm{x}$ - direction and lower boundary is restrained in $\mathrm{x}-\mathrm{y}$ direction. Factor of safety is calculated by strength reduction technique.

By considering six input parameters the various models are formed and simulated using numerical modeling tools. Factor of safety of each simulated model is calculated based on input parameters. Figure 5 shows the simulated model and model with probable plane of failure respectively by finite element method.

Factor of safety of each simulated model is calculated. Selection of parameters is very important step for further analysis by ANN. Graphs are plotted between factor of safety and varying parameter and based on the variation the parameters have been selected for ANN analysis (Rahul 2011).

In this study, ANN is used to find out the factor of safety of coal mine dump slope. Here, 520 dump slope models are used to develop ANN model. The overall dump height, overall slope angle, number of benches, hydrological condition, cohesion of dump material, and angle of internal friction of dump material are taken as input parameters, whereas factor of safety is 


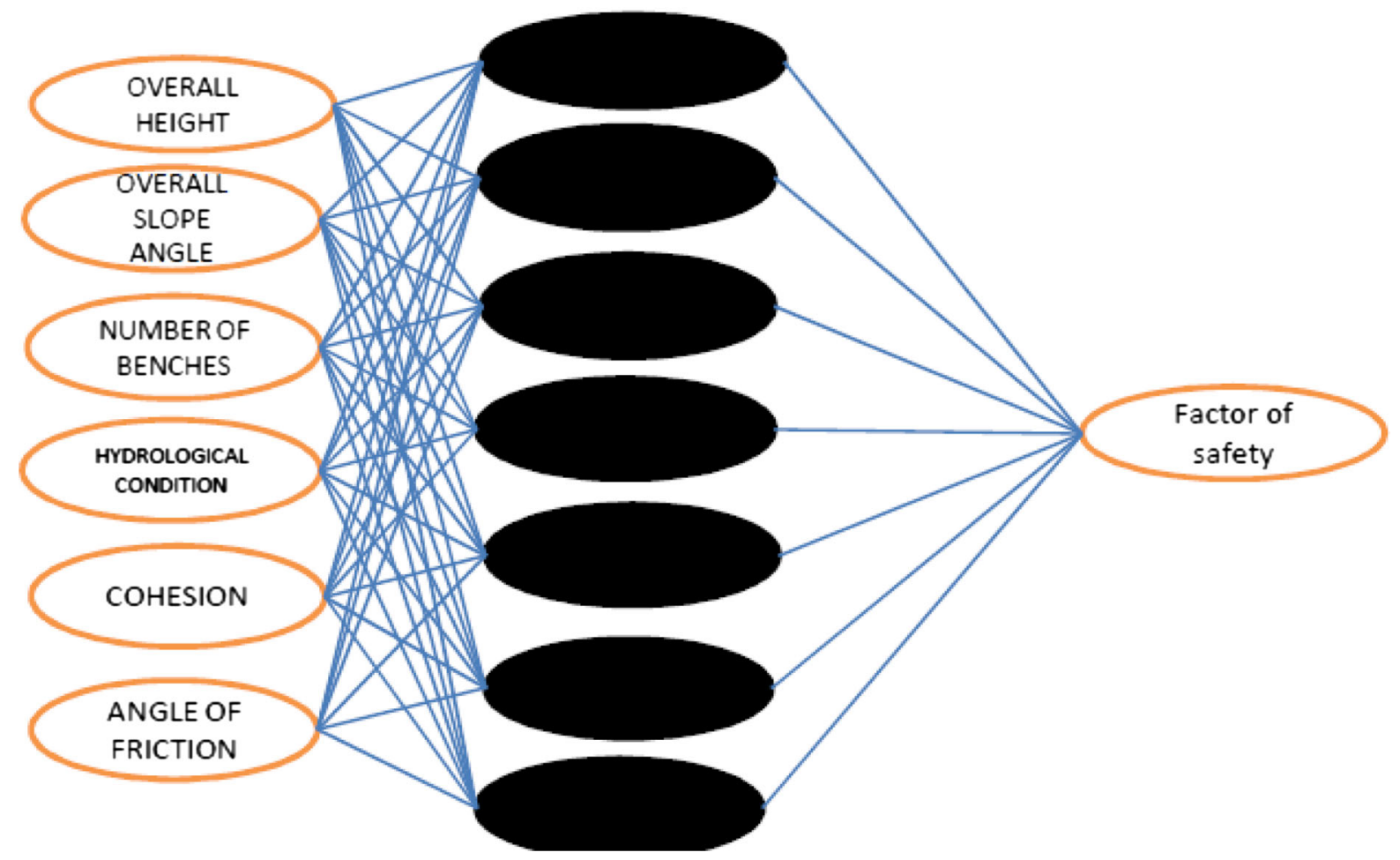

Fig. 3 A three layer network architecture

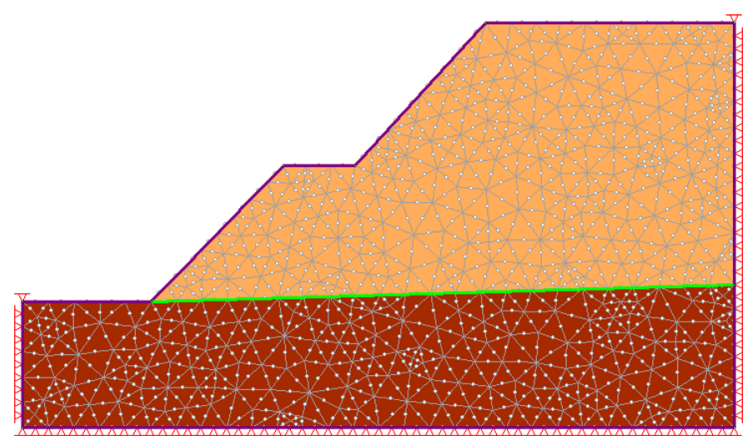

Fig. 4 Descritized model of dump slope by using FEM

considered as output parameter for the development of ANN model.

To test and validate the ANN model, data sets are chosen, which were not used while training of the ANN network. The results are presented in this section to demonstrate the performance of the networks. Test error between the predicted and observed values is taken as the measure of performance. To reach an appropriate architecture, three layer back propagation ANN is selected with one hidden layer. The network with the lowest error is selected as desired network. Table 2 shows the results of some of the tested models while performing analysis using ANN.

The prediction model 6-7-1 with training algorithm BFGS 119 is considered as the optimum model. For evaluation of a model, a comparison between predicted and calculated values of factor of safety was done. For this purpose, graphs are plotted between factor of safety (output) versus factor of safety (target) for training, testing and validation data sets.

Figures 6, 7, 8 show the graph between determined factor of safety using numerical modelling with predicted factors of safety using ANN model for training, testing and validation of ANN models. Here, predicted value of factor of safety by ANN is very closer to the determined factor of safety by numerical modeling methods. Hence, it can be said that ANN modeling can be used for the study and evaluation of complex dump slope stability. 
Fig. 5 Maximum shear stress and FOS diagram by using FEM

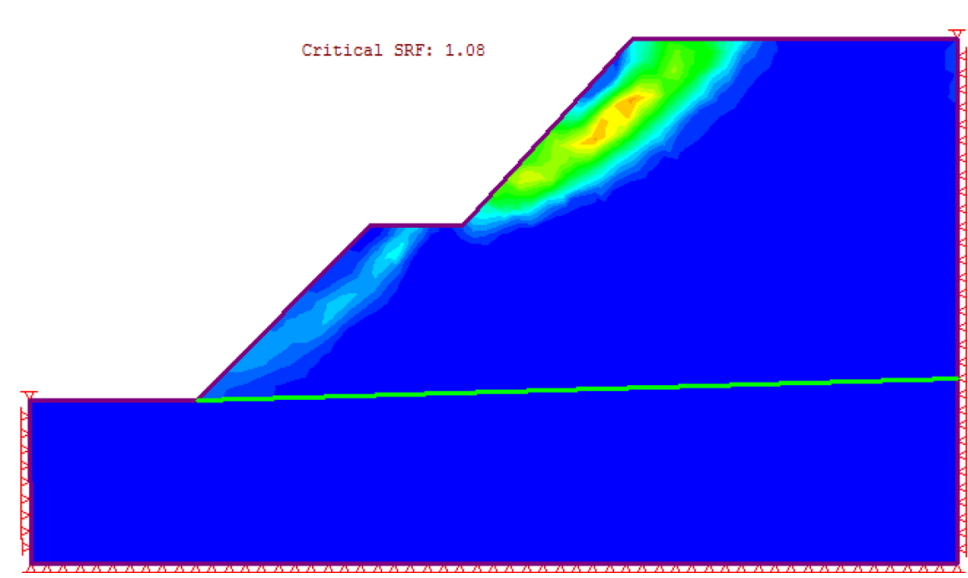

Maximum Shear Strain

$0.00 \mathrm{e}+000$ $1.50 \mathrm{e}-003$ $3.00 \mathrm{e}-003$ $4.50 \mathrm{e}-003$ $6.00 \mathrm{e}-003$ $6.00 \mathrm{e}-003$ $9.00 \mathrm{e}-003$ $1.05 \mathrm{e}-002$ $1.20 \mathrm{e}-002$ 1. $350-002$ $1.50 \mathrm{e}-002$ $1.50 \mathrm{e}-002$
$1.65 \mathrm{e}-002$ $1.65 \mathrm{e}-002$
$1.80 \mathrm{e}-002$ $1.95 \mathrm{e}-002$ $2.10 \mathrm{e}-002$ 2. $25 e-002$ 2.40002 $2.55 \mathrm{e}-002$ $2.70 \mathrm{e}-002$ $2.85 \mathrm{e}-002$ $3.00 \mathrm{e}-002$

Table 2 Results of a comparison between some ANN models

\begin{tabular}{llllllll}
\hline \multicolumn{2}{l}{ Summary of active networks } \\
\hline Index & Model & Training error & Test error & Prediction error & Training algorithm & Hidden activation & Output activation \\
\hline 1 & MLP 6-3-1 & 0.000467 & 0.000176 & 0.000337 & BFGS 108 & Exponential & Exponential \\
2 & MLP 6-5-1 & 0.000297 & 0.000130 & 0.000225 & BFGS 131 & Tanh & Tanh \\
3 & MLP 6-7-1 & 0.000220 & 0.000114 & 0.000170 & BFGS 119 & Tanh & Tanh \\
4 & MLP 6-9-1 & 0.000235 & 0.000140 & 0.000170 & BFGS 118 & Exponential & Sine \\
5 & MLP 6-10-1 & 0.000453 & 0.000171 & 0.000389 & BFGS 68 & Tanh & Exponential \\
\hline
\end{tabular}

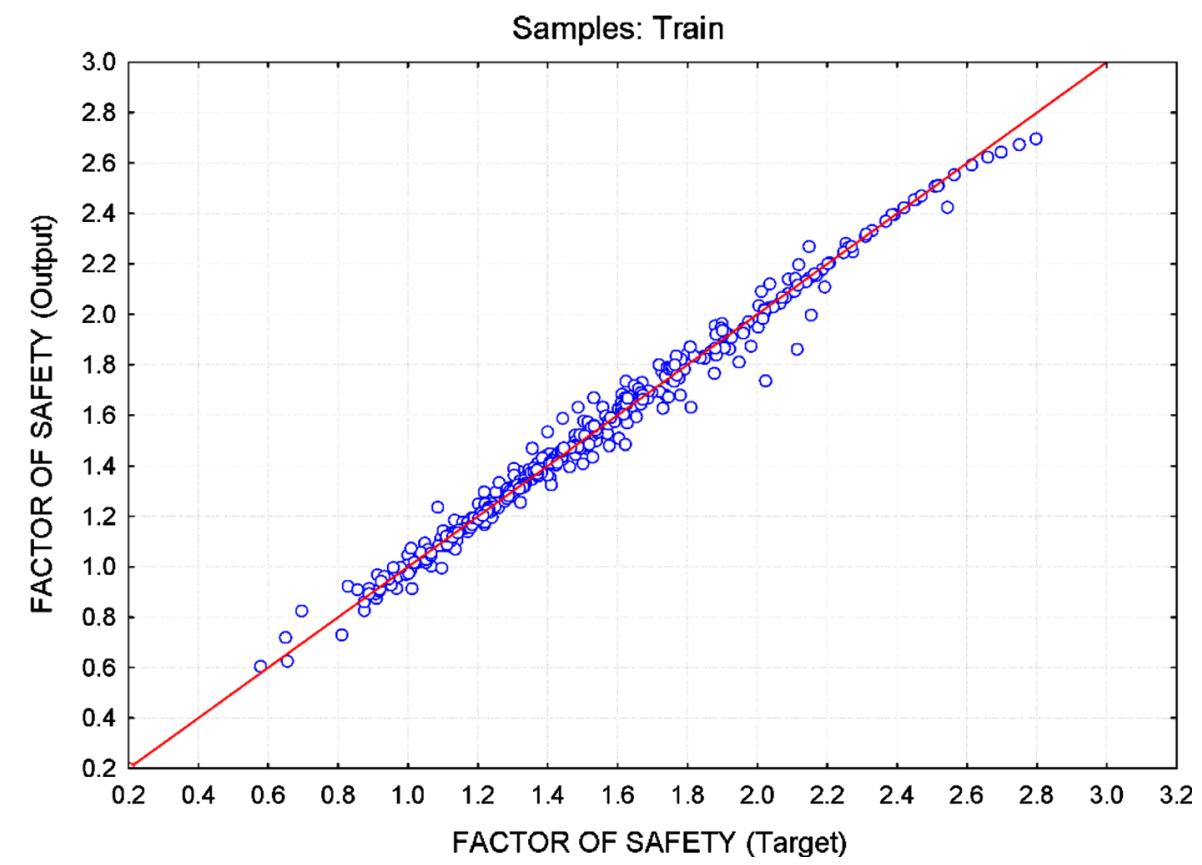

Fig. 6 Targeted and output factor of safety by ANN (for training data) 
Fig. 7 Targeted and output factor of safety by ANN (for test data)

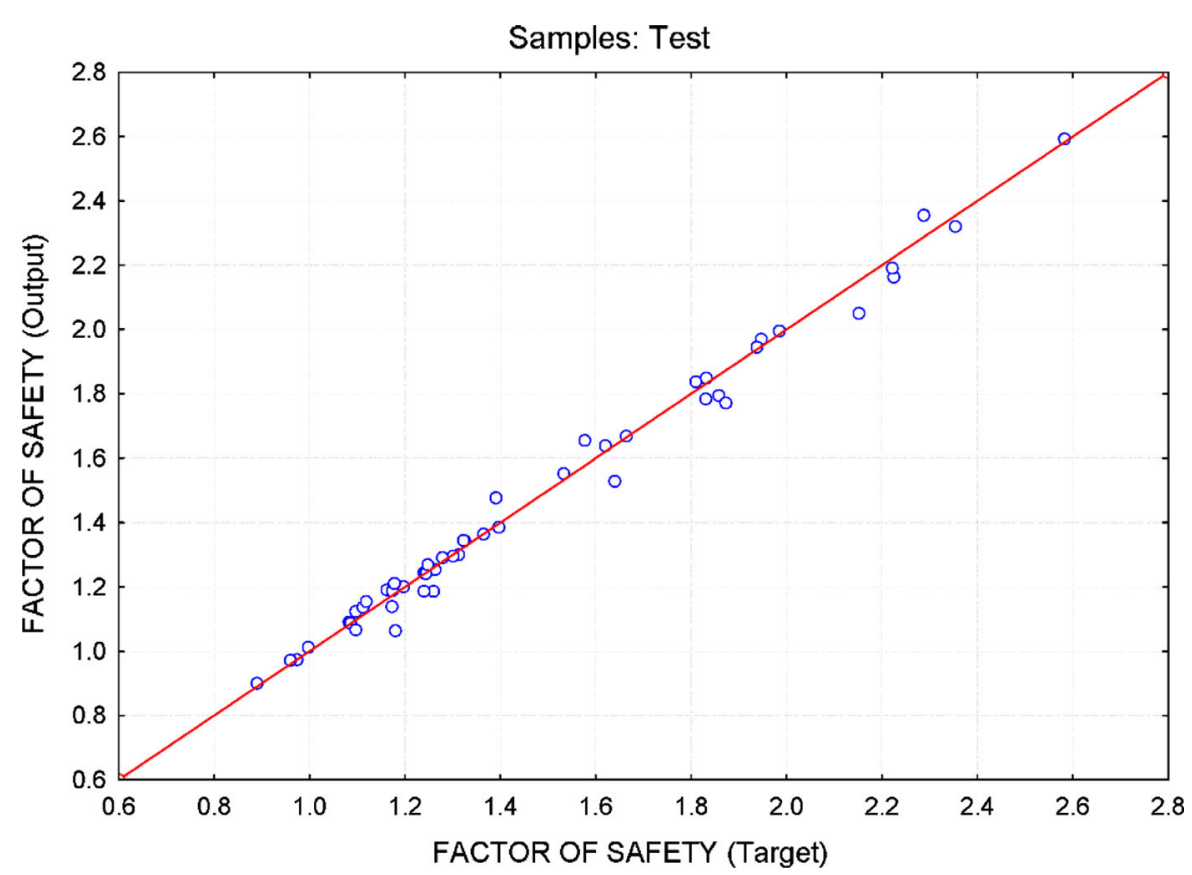

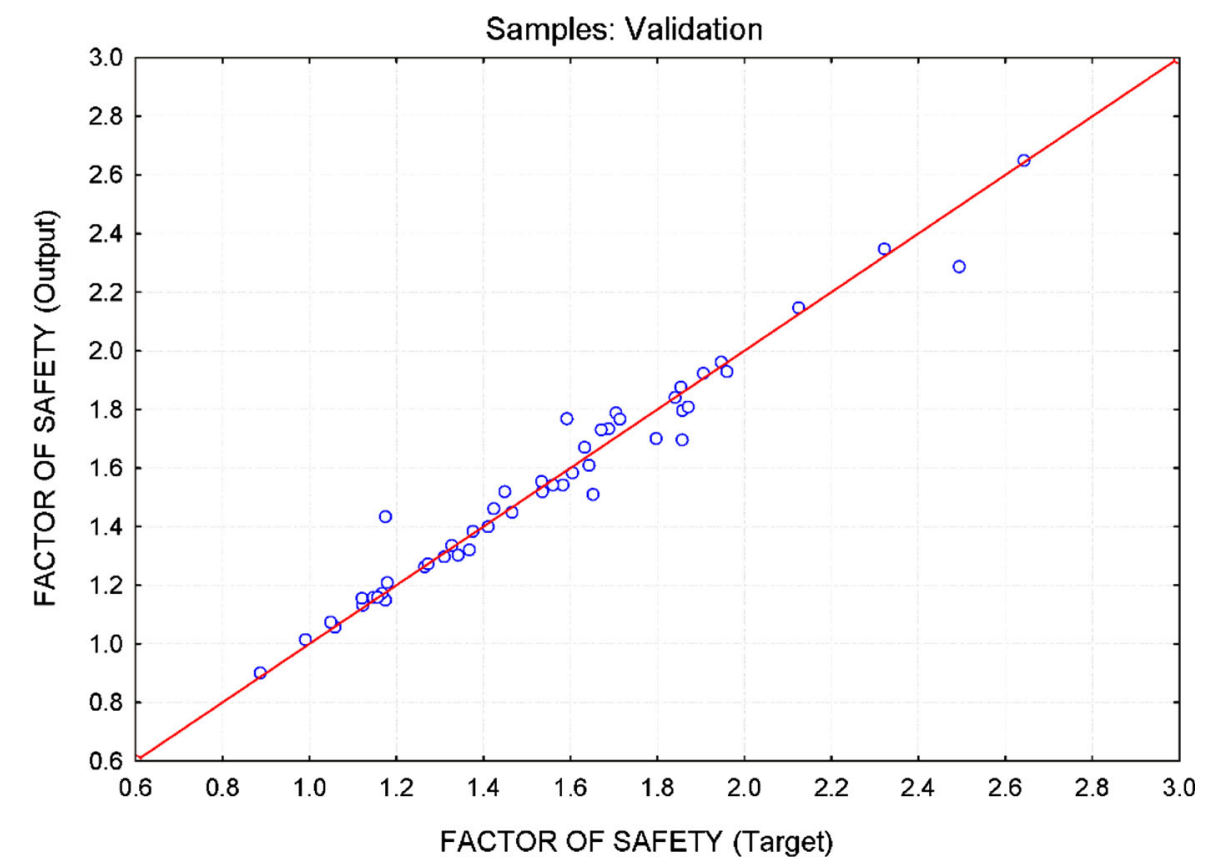

Fig. 8 Targeted and output factor of safety by ANN (for validation data)

\section{Conclusions}

A three layer feed forward back propagation neural network model with 6-7-1 architecture were selected for the present study. Different ANN models were tested based on training, testing and validation data sets. It was found that ANN is able to predict the factor of safety of dump slope with close agreement over 
numerical modelling. Considering the complexity of the relationship among the inputs and outputs, the results obtained by ANN are highly encouraging and satisfactory. Predicted factor of safety value is almost overlapped the measured factor of safety, so ANN can be used for the calculation of factor of safety.

ANN can learn new patterns that are not previously available in the training dataset. ANN can also update knowledge over time as long as more training data sets are presented, and can process information in parallel way. Hence, the technique proves to be economical and easier in comparison to tedious expensive experimental work.

\section{References}

Cała M, Flisiak J (2003) Slope stability analysis with numerical and limit equilibrium methods. In Burczynski, Fedelinski \& Majchrzak (eds) Computer methods in mechanics, CMM-2003

Cundall PA (1976) Explicit finite difference methods in geomechanics, in numerical methods in engineering. Proc EF Conf Numer Methods Geomech 1:132-150

Demuth H, Beale M, Hagan M (2002) Neural network toolbox user's guide. The Mathworks Inc., Natick

DGMS (2010) Circular No. 2 Dhanbad, Dated 06.07.2010 Government of India, Ministry of Labor and Employment, Directorate General of Mines Safety

Duncan JM (1996) State of the art: limit equilibrium and finiteelement analysis of slopes. J Geotech Geoenviron Eng ASCE 122(7):577-596

Fernando J, Nag D (2003) A study of internal overburden dump design and stability analysis for hazelwood power mine, latrobe valley, Victoria, Australia. Application of computers and operations research in the minerals industries. South African Institute of Mining and Metallurgy, pp 267-273

Itasca Consulting Group (1995) FLAC/Slope users' guide, Command Reference, FISH and Theory and Background, Minneapolis

Jing L, Hudson JA (2002) Numerical methods in rock mechanics. Int J Rock Mech Min Sci 39(2002):409-427

Khandelwal M, Singh TN (2002) Prediction of waste dump stability: an intelligent approach. ENTMS, Bhubaneswar, pp 33-45
Khandelwal M, Monjezi M, Dehghani H, Singh TN (2008) Stability analysis of dump slope of a surface mine. Min Eng J 9(10):21-24

Koner R, Chakravarty D (2010) Discrete element approach for mine dump stability analysis. Min Sci Technol 20:809-813

Mayoraz F, Vulliet L (2002) Neural networks for slope movement prediction. Int J Geomech 2(2):153-173

Pourkhosravani A, Kalantari B (2011) A review of current methods for slope stability evaluation. EJGE $16: 1245-1254$

Rahul (2011) Dump slope rating for coal mine and prediction of factor of safety of dump slope by artificial neural network, Unpublished, M.Tech Thesis, Department of Mining Engineering, IIT (BHU), Varanasi

Rai R, Khandelwal M, Jaiswal A (2012) Application of geogrids in waste dump stability: a numerical modeling approach. Environ Earth Sci 66(5):1459-1465

Riley SJ (1995) Aspects of the differences in the erodibility of the waste rock dump and natural surfaces. Ranger Uranium Mine North Territ Aust Appl Geogr 15(4):309-323

Seibi A, Al-Alawi SM (1997) Prediction of fracture toughness using artificial neural networks (ANNs). Eng Fract Mech 56(3):311-319

Shakesby RA, Whitlow JR (1991) Failure of a mine waste dump in Zimbabwe: causes and consequences. Environ Geol Water Sci 18(2):143-153

Singh TN, Khandelwal M (2007) Slope stability: a major concern for coal exploitation. Gondwana Geol Mag 9:127-135

Singhal RK, Vladut T (1987) Design of solid waste dumps and waste disposal in Western Canadian surface mines. In: Proceedings of the 9th annual symposium on geotechnical and geohydrological aspects of waste management. Fort Collins, Publ Chelsea, Michigan: Lewis, pp 123-133, 1-6 Feb

Stuckert B, Balfour J, Fawcett D, Sheehan P, Das B (1989) Study of the dynamic stability of mine waste dumps. CIM Bull 82(927):55-60

Ugai K, Nagase H, Enokido M (1987) Three-dimensional stability analysis of cohesive slopes. In: Proceedings of the Eighth Asian regional conference on soil mechanics and foundation engineering. Kyoto, Publ Japan: Japanese Society for Soil Mechanics and Foundation Engineering. pp 509-512, 20-24 July

Ulusay R, Ekmekci M, Tuncay E, Hasancebi N (2014) Improvement of slope stability based on integrated geotechnical evaluations and hydrogeological conceptualisation at a lignite open pit. Eng Geol 181(1):261-280

Vrkljan I, Ortolan Z, Petras J (1992) Geotechnical problems in designing waste dumps on soft soils. In: Balkema AA (ed) Proceedings of the 6th international symposium on landslides. Christchurch, Publ Rotterdam, pp 255-262, 10-14 Feb 